\title{
Utility of the Free Vascularized Fibula Flap to Reconstruct Oncologic Defects in the Upper Extremity
}

\author{
MATTHEW R. CLAXTON ${ }^{1}$, MATTHEW B. SHIRLEY ${ }^{2}$, KARIM BAKRI $^{2,3}$, \\ PETER S. ROSE ${ }^{2}$, STEVEN L. MORAN $^{2,3}$ and MATTHEW T. HOUDEK ${ }^{2}$ \\ ${ }^{I}$ Mayo Clinic Medical School, Mayo Clinic, Rochester, MN, U.S.A.; \\ ${ }^{2}$ Department of Orthopedic Surgery, Mayo Clinic, Rochester, MN, U.S.A.; \\ ${ }^{3}$ Division of Plastic and Reconstructive Surgery, Mayo Clinic, Rochester, MN, U.S.A.
}

\begin{abstract}
Background/Aim: Non-vascularized methods to reconstruct bone defects following tumor resection are associated with complications. As a result, the free vascularized fibular flap (FVF) has become a mainstay for reconstruction. The purpose of this study was to analyze FVF reconstruction in the upper extremity. Patients and Methods: We reviewed 28 ( 14 female and 14 male, mean age of $29 \pm 20$ years) patients reconstructed with an FVF in the upper extremity following tumor resection. Reconstruction most commonly involved the humerus $(n=17,61 \%)$ and a malignant $(n=23,82 \%)$ tumor. Results: The limb salvage rate was $93 \%(n=26)$, with primary union occurring in $71 \%$ $(n=20)$ of patients. Following bone grafting the overall union was $96 \%(n=27)$ at a mean $13 \pm 11$ months. At most recent follow-up the mean MSTS93 rating was $82 \pm 22 \%$. Conclusion: FVF effectively provided a functional reconstruction following tumor resection. Although, one in four patients will need additional bone grafting, the overall union rate is high.
\end{abstract}

Limb salvage is the preferred treatment in patients undergoing resection of a neoplasm in the extremities $(1,2)$. Following oncologic resection, reconstructive surgeons can encounter large $(>5 \mathrm{~cm})$ segmental bone defects. High rates of infection, nonunion, and fracture have been reported with non-vascularized methods of boney reconstruction (3-7). To provide a biological solution, the free vascularized fibular flap (FVF) has become the gold standard vascularized bone graft (8-12). The benefits of using a vascularized fibula

This article is freely accessible online.

Correspondence to: Matthew T. Houdek, MD, 200 First St. SW, Rochester, MN 55905, U.S.A. Tel: +1 5072842736, Fax: +1 5072664234, e-mail: houdek.matthew@mayo.edu

Key Words: Upper extremity, free vascularized fibula flap, limb salvage, oncologic resection. include its vascular pedicle length, propensity to hypertrophy, and ease of access for harvest (12-15). In the oncologic setting, the unique properties of this flap make it favorable in patients undergoing chemotherapy and radiotherapy (16-18).

High limb salvage rates have been reported in FVF reconstructions following malignant tumor resection $(10,18$ 21). Vascularized fibulas have been shown to be effective in reconstruction of bony defects in the upper extremity, in the setting of traumatic injuries or infection (20,22-27). Despite these reports, there is a paucity of data regarding the long-term limb salvage outcomes following tumor resection and reconstruction with a vascularized fibula in the upper extremity. Our study seeks to analyze rates of overall survival, disease free survival, reoperation free survival, complications and function following limb salvage following FVF reconstruction in the upper extremity after tumor resection.

\section{Patients and Methods}

Following Institutional Review Board (IRB) approval, retrospective review of medical records of patients having undergone reconstruction with a vascularized fibula after tumor resection in the upper extremity between 1995 and 2017 was carried out. Patients with both benign and malignant tumors were included. Thirty patients fitting these criteria were identified. Two patients with less than one year of postoperative follow up were excluded. The study group consisted of 28 [14 females (50\%) and 14 males (50\%)] patients, of which $23(82 \%)$ had malignant tumors and $5(18 \%)$ had benign aggressive tumors requiring an en bloc resection (Table I). The mean age was $29 \pm 20$ years at time of initial operation and osteosarcoma $(n=9,32 \%)$, chondrosarcoma $(n=4,14 \%)$, Ewing sarcoma $(n=4,14 \%)$, and giant cell tumor $(n=4,14 \%)$ were the most common tumor pathologies. Fibular graft recipient sites were the humerus (Figure 1, $n=17,61 \%)$, the radius/ulna $(n=10,36 \%)$, and the clavicle $(\mathrm{n}=1,4 \%)$. Mean graft length was $14 \pm 6 \mathrm{~cm}$, while mean tumor volume at initial operation was $65 \pm 86 \mathrm{~cm}^{3}$. Four $(14 \%)$ of the FVF were composite osteocutaneous flaps. The anastomosis was completed in an end-to-side $(n=20,71 \%)$ and end-to-end $(n=8$, $29 \%$ ) fashion, either using the brachial or a side branch from the brachial $(n=15,54 \%)$, radial $(n=8,29 \%)$, ulnar $(n=2,7 \%)$, profunda 
brachii $(n=1,4 \%)$, posterior collateral $(n=1,4 \%)$, or transverse cervical $(n=1,4 \%)$.

Union was defined as the presence of bridging callus on three of four cortices on anteroposterior and lateral plain radiographs, or an absent osteotomy line at both ends of the graft as reviewed by musculoskeletal radiologists at our institution. The status of patient survival, disease recurrence, and limb salvage was recorded at final follow up, with all patients having at least 1-year of clinical followup. Limb salvage failure was defined as amputation or fibular graft removal. Functional outcomes were assessed using Musculoskeletal Tumor Society (MSTS93) ratings and Mankin functional outcome scores $(28,29)$.

Patients were monitored postoperatively for recurrence at our institution with radiographs and cross sectional imaging of the involved extremity and, depending on the histology of the tumor, a computed tomographic (CT) scan of the chest or chest radiograph for tumor recurrence was performed every 3 to 4 months for the first 2 years, then every 6 months for years 2 to 5 , and then annually for years 5 to 10 . Outside imaging was sent to our institution for review when patients were unable to travel for follow up appointments. Mean follow up was $7 \pm 5$ years.

Overall survival, disease free survival, reoperation, primary union, and limb salvage were determined using the Kaplan-Meier model. Odds ratios were calculated to assess risk factors for failure of primary union. Statistical significance was assigned for $p$-values $<0.05$.

\section{Results}

Fibular graft union. Primary union occurred in 20 patients $(71 \%)$ at a mean of $9 \pm 8$ months (Table II) postoperatively. Of the eight patients who did not unite primarily, seven ultimately united after undergoing subsequent operative autogenous bone grafting at a mean of $8 \pm 3$ months postoperatively. Following this, 27 patients $(96 \%)$ united at a mean of $13 \pm 11$ months. One patient $(4 \%)$ had a persistent non-union in the humerus despite subsequent operative grafting and underwent a total elbow arthroplasty.

Female gender was associated with failure of primary union $(\mathrm{OR}=13.0,95 \% \mathrm{CI}=1.32-128.11 ; \mathrm{p}=0.03$ ) (Table III). In addition, primary union did not occur in any of the patients with diabetes $(n=2)$. Of the patients with diabetes $(n=2)$, one patient achieved overall union after secondary operative grafting and one patient failed to unite overall. Age, tumor location above the elbow, radiotherapy, and adjuvant chemotherapy were not associated with failure to achieve primary union.

Complications. Complications occurred in 18 (64\%) patients postoperatively (Table II). Seventeen patients (61\%) experienced recipient site complications (Table II) including delayed union $(n=8)$, fibular graft fracture $(n=4)$, and infection $(n=4)$. Other recipient site complications included ulnar impaction $(n=1)$, compartment syndrome $(n=1)$, hematoma $(n=1)$, and hardware loosening $(n=1)$. Two patients $(7 \%)$ experienced donor site complications including claw toes $(n=1)$ and wound dehiscence $(n=1)$.
Table I. Patient and disease demographics.

\begin{tabular}{lc}
\hline Mean age & $29 \pm 20$ \\
Pediatric patients & 12 \\
Age<40 & $19(68 \%)$ \\
Female (Male) & $14(14)$ \\
Mean graft length & $14 \pm 6 \mathrm{~cm}$ \\
Mean tumor volume & $65 \pm 86 \mathrm{~cm}^{3}$ \\
Pathology & \\
Osteosarcoma & $9(32 \%)$ \\
Chondrosarcoma & $4(14 \%)$ \\
Ewing sarcoma & $4(14 \%)$ \\
Giant cell & $4(14 \%)$ \\
Multiple myeloma & $3(11 \%)$ \\
Desmoplastic fibroma & $1(4 \%)$ \\
Liposarcoma & $1(4 \%)$ \\
Epithelioid hemangioendothelioma & $1(4 \%)$ \\
Synovial sarcoma & $1(4 \%)$ \\
Location & \\
Humerus & $17(61 \%)$ \\
Radius/Ulna & $10(36 \%)$ \\
Clavicle & $1(4 \%)$ \\
\hline
\end{tabular}

Table II. Data on fibular graft outcomes and complications.

\begin{tabular}{lc}
\hline Mean follow-up & $7 \pm 5$ years \\
Mean time to union & $13 \pm 11$ \\
Overall rate of union & $27(96 \%)$ \\
Rate of primary union & $20(71 \%)$ \\
Rate of limb salvage & $26(93 \%)$ \\
Complication rate & $18(64 \%)$ \\
Recipient site complication rate & $17(61 \%)$ \\
Delayed union & $8(29 \%)$ \\
Fibular graft fracture & $4(14 \%)$ \\
Infection & $4(14 \%)$ \\
Nerve palsy & $2(7 \%)$ \\
Hardware pain & $2(7 \%)$ \\
Other & $4(14 \%)$ \\
Donor site complication rate & $2(7 \%)$ \\
Claw toes & $1(4 \%)$ \\
Wound dehiscence & $1(4 \%)$ \\
\hline
\end{tabular}

Other recipient site complications: ulnar shortening $(n=1)$, compartment syndrome $(\mathrm{n}=1)$, hematoma $(\mathrm{n}=1)$, hardware loosening $(\mathrm{n}=1)$.

Complications resulted in reoperations in 11 (39\%) patients, with $4(14 \%)$ patients having multiple operations. In addition to the patients who underwent repeat autogenous bone grafting $(n=8)$, other indications for reoperation of complications were fixation of fibular graft fracture $(n=2)$, irrigation and debridement for infection $(n=2)$, ulnar shortening osteotomy $(n=1)$, hematoma evacuation $(n=1)$, and compartment release $(n=1)$.

Functional outcomes. Following reconstruction, the mean MSTS93 rating for the group was $82 \pm 22 \%$ (Table IV). A 

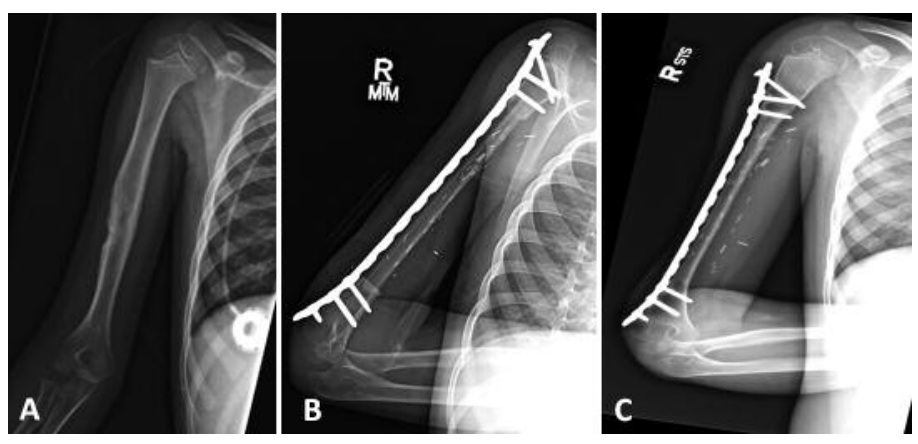

Figure 1. Preoperative radiograph of a pediatric patient with a destructive lesion in the humerus (A) which was biopsied and found to be an Ewing sarcoma. The fibula was then intussuscepted into the cut bone ends, and compressed and spanned with a locking plate (B). At most recent follow-up, the fibula has hypertrophied and the humerus has had continued growth $(C)$. good to excellent Mankin functional outcome score was achieved in 20 patients $(71 \%)$. Reconstruction failures occurred in 3 patients $(11 \%)$ that died from distant metastases and 2 patients (7\%) who underwent amputation to treat local recurrence.

Disease-specific and recurrence-free survival. Overall disease-free 2-, 5-, 10-, and 15-year recurrence free survival rates were $93 \%, 76 \%, 70 \%$, and $47 \%$, respectively. Eight patients $(29 \%)$ experienced disease recurrence at a mean time of $4 \pm 5$ years after limb salvage surgery. Among these, 5 patients $(18 \%)$ experienced distant metastases, while 3 patients $(11 \%)$ experienced local recurrence. Sites of distant metastasis were the lung $(n=3)$, ilium $(n=1)$, and retroperitoneum $(\mathrm{n}=1)$. Local recurrence 2-, 5-, 10-, and 15year survival rates were $96 \%, 91 \%, 84 \%$, and $84 \%$, respectively. For the same time points, distant metastasis survival rates were $96 \%, 83 \%, 83 \%$, and $55 \%$, respectively.

\section{Discussion}

The free vascularized fibular flap has proved to be a workhorse flap for extremity bony defect reconstruction (9, 13, 15, 16, 30-33). Most published studies report on a combination of various anatomical locations and indications for the fibula flap with relatively few studies focusing on oncologic upper limb salvage with a fibula $(10,20,22-24$, $31,34)$. We sought out to specifically investigate outcomes of limb salvage with a vascularized fibular flap following tumor resection in the upper extremity.

The overall limb salvage rate was high, at 93\% $(n=26)$. For the two patients with failed limb salvage, amputation occurred 3- and 6-years after initial limb salvage surgery. Both patients originally had a malignant tumor of the humerus and required forequarter amputation for local recurrence, and both died during follow up. In a series of oncologic limb salvage operations with a vascularized fibula at the humerus, there have been historically no cases of amputation $(20,24)$. In both studies, no patients had local disease recurrence $(20,24)$. Provided local recurrence does not occur, amputation can be avoided in many tumor cases with upper extremity limb salvage surgery using a vascularized fibula.

The rate of primary union in this study $(71 \%)$ is similar to other previous reports in the upper extremity $(23,24)$. Larger studies with mixed anatomical locations yielded similar primary union rates and overall union rates to ours, with a similar mean time to union $(10,18,19)$. Less favorable rates of union and times to union have been reported in reconstruction of defects in the humerus or clavicle with a vascularized fibula $(20,23)$. In the current series, union outcomes in the humerus or clavicle were similar to the cohort as a whole, with $72 \%(n=13)$ achieving primary union at a mean time of $10 \pm 10$ months. Likewise, no association was identified between failure of primary union and reconstruction location proximal to the elbow. In contrast to our findings, a similar series consisting of upper and lower extremity limb salvage operations reported adjuvant chemotherapy to be associated with failed primary union, while gender was not associated with failed primary union in this study (10).

Complications were common, with $64 \%(n=18)$ of patients experiencing at least one complication. Similar to other reports, infection, graft fracture, and delayed union were the most frequently observed complications $(7,10,18-20,24)$. Delayed union was effectively managed with additional autogenous operative bone grafting in $88 \%(n=7)$ of cases of delayed union. The patient which failed to unite after secondary grafting went on to have a total elbow arthroplasty and humeral replacement, followed by amputation for local recurrence. Three of four fibular flap fractures occurred at the humerus, with $18 \%$ of humerus reconstructions experiencing fracture. Graft fractures at the humerus were treated using open reduction and internal fixation $(\mathrm{n}=1)$, sling immobilization $(n=1)$, and shoulder spica cast immobilization $(n=1)$. Open reduction and internal fixation was used in the one graft fracture at the radius. Radiographic evidence of healing was achieved in all cases of fibular graft fracture. 
Table III. Factors associated with failure of primary union.

\begin{tabular}{lcc}
\hline Patient factors & $\begin{array}{c}\text { Odds ratio } \\
(95 \% \mathrm{CI})\end{array}$ & $p$-Value \\
\hline Pediatric & $0.73(0.14-3.94)$ & 1.00 \\
Age $<40$ & $0.33(0.06-1.85)$ & 0.37 \\
Female & $13.0(1.32-128.11)$ & $\mathbf{0 . 0 3}$ \\
Above elbow & $0.90(0.16-4.92)$ & 1.00 \\
Diabetes & $\infty$ & 0.07 \\
Tobacco use & $1.89(0.25-14.19)$ & 0.61 \\
Chemotherapy during postoperative period & $0.54(0.10-2.84)$ & 0.67 \\
History of radiation & $2.40(0.40-14.56)$ & 0.63 \\
Use of iliac crest bone graft & $0.60(0.11-3.21)$ & 0.69 \\
Spanning locking plate & $1.67(0.31-8.93)$ & 0.69 \\
\hline
\end{tabular}

Bold value shows significance.

Following reconstruction, a majority of patients experienced a "good" to "excellent" Mankin functional outcome, while mean MSTS93 rating for the group was high. Disease recurrence and amputation were primary causes for failed Mankin scores and low MSTS93 ratings. Provided local recurrence is avoided, most patients can experience a functional outcome following FVF limb salvage in the upper extremity.

Our study has some limitations. Although this is a large series of upper extremity reconstruction, the numbers remain small and as such limited the analysis we were able to perform. In addition, the resections span a long time period with multiple surgeons involved in the care, that being said, all resections were performed by subspecialty training orthopedic oncologists and reconstructive surgeons. Each resection was different based on the unique characteristics of the tumor and the tissues sacrificed for an oncological resection, and as such each resection was different. Also, the retrospective nature of this study limits the quantity and quality of data available for analysis.

Overall limb salvage of the upper extremity can be reliably carried out with a vascularized fibula following resection of a benign or malignant tumor. Although complications are common, following reconstruction, patients should expect excellent functional outcomes following graft union.

\section{Conflicts of Interest}

No conflicts of interest are declared by any Author on this study.

\section{Authors' Contributions}

Claxton: Drafting of initial and final manuscript, data collection, data analysis; Shirley: Drafting of initial and final manuscript, data collection, data analysis; Bakri: Review and editing of final manuscript; Rose: Review and editing of final manuscript; Moran:
Table IV. Functional outcomes after limb salvage.

\begin{tabular}{lc}
\hline & Outcome measure \\
\hline MSTS93 rating & \\
Mean (SD) & $82 \pm 22 \%$ \\
Mankin rating & \\
Excellent & $13(46 \%)$ \\
Good & $7(25 \%)$ \\
Fair & $2(7 \%)$ \\
Failure & $5(18 \%)$ \\
Amputation & $2(7 \%)$ \\
Death following distant recurrence & $3(11 \%)$ \\
\hline
\end{tabular}

MSTS: Musculoskeletal tumor society.

Review and editing of final manuscript, supervision; Houdek: Drafting of initial and final manuscript, data analysis, supervision.

\section{Acknowledgements}

No disclosures of funding received for this work from NIH, Welcome Trust, or HHMI. Each author certifies that his or her institution approved the human protocol for this investigation and that all investigations were conducted in conformity with ethical principles of research.

\section{References}

1 Lewis VO: What's new in musculoskeletal oncology. J Bone Joint Surg Am 91(6): 1546-1556, 2009. PMID: 19487537. DOI: 10.2106/jbjs.i.00375

2 Simon MA, Aschliman MA, Thomas N and Mankin HJ: Limbsalvage treatment versus amputation for osteosarcoma of the distal end of the femur. J Bone Joint Surg Am 68(9): 1331-1337, 1986. PMID: 3465732.

3 Berrey BH Jr., Lord CF, Gebhardt MC and Mankin HJ: Fractures of allografts. Frequency, treatment, and end-results. J Bone Joint Surg Am 72(6): 825-833, 1990. PMID: 2365716.

4 Donati D, Di Liddo M, Zavatta M, Manfrini M, Bacci G, Picci P, Capanna R and Mercuri M: Massive bone allograft reconstruction in high-grade osteosarcoma. Clin Orthop Relat Res 377: 186-194, 2000. PMID: 10943201. DOI: 10.1097/00003086-20000800000025

5 Hornicek FJ, Gebhardt MC, Tomford WW, Sorger JI, Zavatta M, Menzner JP and Mankin HJ: Factors affecting nonunion of the allograft-host junction. Clin Orthop Relat Res 382: 87-98, 2001. PMID: 11154010. DOI: 10.1097/00003086-200101000-00014

6 Moran SL, Shin AY and Bishop AT: The use of massive bone allograft with intramedullary free fibular flap for limb salvage in a pediatric and adolescent population. Plast Reconstr Surg 118(2): 413-419, 2006. PMID: 16874212. DOI: 10.1097/01.prs.00002 27682.71527.2b

7 O'Connor MI, Sim FH and Chao EY: Limb salvage for neoplasms of the shoulder girdle. Intermediate reconstructive and functional results. J Bone Joint Surg Am 78(12): 1872-1888, 1996. PMID: 8986665. DOI: 10.2106/00004623-199612000-00011 
8 Brown KL: Limb reconstruction with vascularized fibular grafts after bone tumor resection. Clin Orthop Relat Res 262): 64-73, 1991. PMID: 1984933.

9 Han CS, Wood MB, Bishop AT and Cooney WP, 3rd: Vascularized bone transfer. J Bone Joint Surg Am 74(10): 14411449, 1992. PMID: 1469003.

10 Houdek MT, Wagner ER, Bishop AT, Shin AY, Rose PS, Sim FH and Moran SL: Complications and long-term outcomes of free fibula reconstruction following resection of a malignant tumor in the extremities. Plast Reconstr Surg 139(2): 510e-519e, 2017. PMID: 28121893. DOI: 10.1097/prs.0000000000003004

11 Hsu RW, Wood MB, Sim FH and Chao EY: Free vascularised fibular grafting for reconstruction after tumour resection. J Bone Joint Surg Br 79(1): 36-42, 1997. PMID: 9020442. DOI: 10.1302/0301-620x.79b1.6818

12 Muramatsu K, Hashimoto $\mathrm{T}$, Tominaga $\mathrm{Y}$ and Taguchi $\mathrm{T}$ : Vascularized bone graft for oncological reconstruction of the extremities: Review of the biological advantages. Anticancer Res 34(6): 2701-2707, 2014. PMID: 24922630.

13 Beris AE, Lykissas MG, Korompilias AV, Vekris MD, Mitsionis GI, Malizos KN and Soucacos PN: Vascularized fibula transfer for lower limb reconstruction. Microsurgery 31(3): 205-211, 2011. PMID: 21360586. DOI: 10.1002/micr.20841

14 Brunelli GA, Vigasio A and Brunelli GR: Microvascular fibular grafts in skeleton reconstruction. Clin Orthop Relat Res 314): 241-246, 1995. PMID: 7634641.

15 de Boer HH and Wood MB: Bone changes in the vascularised fibular graft. J Bone Joint Surg Br 71(3): 374-378, 1989. PMID: 2722923.

16 Canosa R and Gonzalez del Pino J: Effect of methotrexate in the biology of free vascularized bone grafts. A comparative experimental study in the dog. Clin Orthop Relat Res 301: 291301, 1994. PMID: 8156690.

17 Taylor GI, Miller GD and Ham FJ: The free vascularized bone graft. A clinical extension of microvascular techniques. Plast Reconstr Surg 55(5): 533-544, 1975. PMID: 1096183. DOI: 10.1097/00006534-197505000-00002

18 Chen CM, Disa JJ, Lee HY, Mehrara BJ, Hu QY, Nathan S, Boland P, Healey $\mathrm{J}$ and Cordeiro PG: Reconstruction of extremity long bone defects after sarcoma resection with vascularized fibula flaps: A 10-year review. Plast Reconstr Surg 119(3): 915-924; discussion 925-916, 2007. PMID: 17312496. DOI: 10.1097/01.prs.0000252306.72483.9b

19 Eward WC, Kontogeorgakos V, Levin LS and Brigman BE: Free vascularized fibular graft reconstruction of large skeletal defects after tumor resection. Clin Orthop Relat Res 468(2): 590-598, 2010. PMID: 2806986. DOI: 10.1007/s11999-009-1053-x

20 Rose PS, Shin AY, Bishop AT, Moran SL and Sim FH: Vascularized free fibula transfer for oncologic reconstruction of the humerus. Clin Orthop Relat Res 438: 80-84, 2005. PMID: 16131873. DOI: 10.1097/01.blo.0000179586.34727.5b

21 Zaretski A, Amir A, Meller I, Leshem D, Kollender Y, Barnea Y, Bickels J, Shpitzer T, Ad-El D and Gur E: Free fibula long bone reconstruction in orthopedic oncology: A surgical algorithm for reconstructive options. Plast Reconstr Surg 113(7): 1989-2000, 2004. PMID: 15253188. DOI: 10.1097/01.prs.0000122213.82011.c5

22 Soucacos PN, Korompilias AV, Vekris MD, Zoubos A and Beris AE: The free vascularized fibular graft for bridging large skeletal defects of the upper extremity. Microsurgery 31(3): 190-197, 2011. PMID: 21374713. DOI: 10.1002/micr.20862
23 Wood MB: Upper extremity reconstruction by vascularized bone transfers: Results and complications. J Hand Surg Am 12(3): 422-427, 1987. PMID: 3584891. DOI: 10.1016/s03635023(87)80017-5

24 Gebert C, Hillmann A, Schwappach A, Hoffmann C, Hardes J, Kleinheinz J and Gosheger G: Free vascularized fibular grafting for reconstruction after tumor resection in the upper extremity. J Surg Oncol 94(2): 114-127, 2006. PMID: 16847920. DOI: $10.1002 /$ jso. 20326

25 Adani R, Delcroix L, Innocenti M, Marcoccio I, Tarallo L, Celli A and Ceruso M: Reconstruction of large posttraumatic skeletal defects of the forearm by vascularized free fibular graft. Microsurgery 24(6): 423-429, 2004. PMID: 15378573. DOI: 10.1002/micr.20067

26 Houdek MT, Wagner ER, Wyles CC, Nanos GP, 3rd and Moran SL: New options for vascularized bone reconstruction in the upper extremity. Semin Plast Surg 29(1): 20-29, 2015. PMID: 25685100. DOI: $10.1055 / \mathrm{s}-0035-1544167$

27 Yajima H, Tamai S, Ono H, Kizaki K and Yamauchi T: Free vascularized fibula grafts in surgery of the upper limb. J Reconstr Microsurg 15(7): 515-521, 1999. PMID: 10566580. DOI: $10.1055 / \mathrm{s}-2007-1000131$

28 Mankin HJ, Doppelt SH, Sullivan TR and Tomford WW: Osteoarticular and intercalary allograft transplantation in the management of malignant tumors of bone. Cancer 50(4): 613630, 1982. PMID: 7046906. DOI: 10.1002/10970142(19820815)50:4<613::aid-cncr2820500402>3.0.co;2-1

29 Enneking WF, Dunham W, Gebhardt MC, Malawar M and Pritchard DJ: A system for the functional evaluation of reconstructive procedures after surgical treatment of tumors of the musculoskeletal system. Clin Orthop Relat Res 286): 241246, 1993. PMID: 8425352.

30 Ihara K, Doi K, Yamamoto M and Kawai S: Free vascularized fibular grafts for large bone defects in the extremities after tumor excision. J Reconstr Microsurg 14(6): 371-376, 1998. PMID: 9734837. DOI: $10.1055 / \mathrm{s}-2007-1000193$

31 Minami A, Kasashima T, Iwasaki N, Kato H and Kaneda K: Vascularised fibular grafts. An experience of 102 patients. J Bone Joint Surg Br 82(7): 1022-1025, 2000. PMID: 11041594. DOI: $10.1302 / 0301-620 x .82 b 7.10332$

32 Sun $\mathrm{Y}$, Zhang $\mathrm{C}$, Jin $\mathrm{D}$, Sheng $\mathrm{J}$, Cheng $\mathrm{X}$ and Zeng B: Treatment for large skeletal defects by free vascularized fibular graft combined with locking plate. Arch Orthop Trauma Surg 130(4): 473-479, 2010. PMID: 19471948. DOI: 10.1007/s00402009-0898-5

33 Weiland AJ, Moore JR and Daniel RK: Vascularized bone autografts. Experience with 41 cases. Clin Orthop Relat Res 174: 87-95, 1983. PMID: 6339145.

34 Kubo T, Furuta T and Ochi M: More than 20-year follow-up after vascularised fibula head graft for oncological shoulder joint reconstruction. Anticancer Res 36(1): 301-305, 2016. PMID: 26722057.
Received March 28, 2020

Revised April 3, 2020

Accepted April 6, 2020 